\title{
The Dark Side of Engaging With Social Networking Sites (SNS)
}

\author{
Eileen O'Donnell \\ Technological University Dublin, eileen.odonnell@TUDublin.ie \\ Liam O'Donnell \\ Technological University Dublin, liam.odonnell@tudublin.ie
}

Follow this and additional works at: https://arrow.tudublin.ie/buschmanbk

Part of the Business Commons

\section{Recommended Citation}

O'Donnell, E., \& O'Donnell, L. (2020). The dark side of engaging with Social Networking Sites (SNS). In M. Khosrow-Pour (Ed.), Encyclopedia of Criminal Activities and the Deep Web (Vol. 2, pp. 615-627). Hershey, Pennsylvania: Information Resources Management Association, IGI Global, USA.

This Book Chapter is brought to you for free and open access by the School of Management at ARROW@TU Dublin. It has been accepted for inclusion in Books/Book Chapters by an authorized administrator of ARROW@TU Dublin. For more information, please contact arrow.admin@tudublin.ie, aisling.coyne@tudublin.ie, gerard.connolly@tudublin.ie.

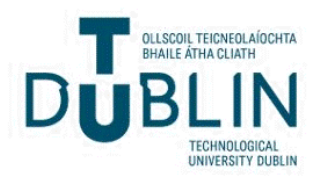




\section{The Dark Side of Engaging With Social Networking Sites (SNS)}

\section{Eileen O'Donnell}

Technological University Dublin, Ireland

Liam O'Donnell

Technological University Dublin, Ireland

\section{INTRODUCTION}

Although engagement with the deep or dark web may seem to some to be intimating or possibly threatening, the surface web similarly presents users with challenges which may also be detrimental to one's peace of mind or health. This paper reviews the dark side of engaging with the surface web through the use of Social Networking Sites (SNS), the issues discussed in this paper will also be relevant to users' engagement with the deep and dark web. While SNS have the potential to impact positively on adolescent's health and well-being, the use of SNS has the potential for exposure to possible risks (Guinta \& John, 2018). SNS include: Facebook (2018), QZone (2018), YouTube (2018), Twitter (2018), Reddit (2018), Pinterest (2018), Tumblr (2018), Flickr (2018), Whatsapp (2018), Snapchat (2018), Viber (2018), Google+ (2018), Instagram (2018), LinkedIn (2018), Skype (2018), Tinder (2018), Grindr (2018), amongst many others used around the world. Computer algorithms are used to draw people in to frequent use of SNS. Once someone is online and engaging with SNS, more computer algorithms are used to keep the persons attention and hence increase the amount of time spent online. Recommender systems are used to enhance collaborative filtering algorithms which encourage users engagement with Social Networking Sites (Eirinaki, Gao, Varlamis, \& Tserpes, 2018; Liu \& Lee, 2010). The dark side of engaging with SNS includes: addiction or addictive behavior, child pornography, cyberbullying, fake news, Fear Of Missing Out (FOMO), social comparisons, stalking, amongst many others, which can all lead to neglect of other duties, sleep deprivation, loneliness, isolation, depression, and so forth. The aim of this chapter is to review the negative effects of engaging with SNS and consider what solutions can be proposed to alleviate the damage caused by engagement with SNS.

\section{BACKGROUND}

"It is increasingly observable that social media present enormous risks for individuals, communities, firms, and even for society as a whole" (Baccarella, Wagner, Kietzmann, \& McCarthy, 2018, p. 431). Now that we as a society are aware of the possible dangers posed by social media, it is time to address all of these potential risks with individuals, communities, organisations, and so forth. By identifying and highlighting these risks and through ensuring that individuals, communities, and organisations are made aware of these risks, only then will it be possible to successfully deal with such risks. "Even with social media executives admitting that their platforms have deleterious impacts, users tend not to question the short- and long-term implications and potential risks of their choices" (Baccarella et al.,

DOI: $10.4018 / 978-1-5225-9715-5 . \operatorname{ch} 042$

Copyright $\odot$ 2020, IGI Global. Copying or distributing in print or electronic forms without written permission of IGI Global is prohibited. 
2018, p. 432). Users should be encouraged to question the short and long term risks of engaging with SNS. This is a discussion in which all members of society should engage, not just parents and school teachers. Many adults are experiencing problems as a result of excessive engagement with SNS. This paper reviews some of the negative effects of engaging with SNS on the habits (addiction and addictive behaviour, exposure to child pornography, cyberbullying) and mental health (fake news, fear of missing out, social comparisons, stalking) of users. In addition, users are encouraged to consider how their use of SNS may be impacting the lives of others (family members, work colleagues, and other online users).

\section{The Dark Web}

The dark web represents a number of anonymously created websites which are hosted on the deep web. The dark web is intentionally hidden (Paul, 2018), the content is not indexed for search engines to find, unlike the surface web where the content is indexed and accessible to standard web browsers, for example, Google Chrome (Google, 2019), Mozilla Firefox (Firefox, 2019), or Microsoft Internet Explorer (Microsoft, 2019). The surface web is the opposite of the deep web (also known as the invisible web and the hidden web). The surface web is easily accessible to all using standard web browsers on the internet. The deep web and the dark web are not accessible through standard web search engines and web crawlers.

In a research study conducted by Dalins, Wilson \& Carman (2018) the findings suggest that "criminality on this 'dark web' is based more upon greed and desire, rather than any particular political motivations" (Dalins et al., 2018, p. 62). The dark web refers to a number of anonymously hosted websites on the deep web which are accessible by using specialized software to hide the Internet Protocol (IP) address. IP addresses are assigned to every device that connects to the internet. A Public IP address can be accessed over the internet, a Private IP address cannot be accessed over the internet but are used in internal networks. A Global IP address is specific to a particular network and all devices using that network. Internet Service Providers (ISP) assign Global IP addresses.

The dark web is part of the World Wide Web (WWW) that is only accessible through the use of specialized software (Monk, Mitchell, Frank, \& Davies, 2018). The dark web is an encrypted network (to enforce anonymity) that exists predominantly between The Onion Routing (TOR) encryption tools, servers, and their users (Monk et al., 2018). Users of the dark web have the option to remain anonymous and untraceable. Methods employed to access the dark web are quite involved therefore the dark web is not used by the average user. "The globalization of technology and rise of popularity in cryptocurrencies has changed the face of black-market trade and the actors that carry out these crimes" (Paul, 2018, p. 1). Law enforcement agencies and Government Departments are continuously playing catch up in trying to deal with innovations adopted by black market traders to conceal the money trail. "The internet provides an ever-growing number of ways to hide, launder money and pursue a vast range of criminal activities in ways that are difficult to detect or deter" (Slaughter, 2018, p. 118). The handling of criminal activities conducted online is challenging, expensive and requires sufficient quantities of technical resources. The dark web can be used for illegal activities, such as: the sale of drugs (Mackey, 2018; Norbutas, 2018; Porter, 2018), firearms (Porter, 2018), untraceable cryptocurrencies such as Bitcoin (Paul, 2018), child pornography (Dalins et al., 2018), trade in exotic animals (Paul, 2018), sale and purchase of credit card details (Hayes, Cappa, \& Cardon, 2018), identify theft (Hayes et al., 2018), money laundering (Dalins et al., 2018; Wegberg, Oerlemans, \& Deventer, 2018), amongst others. The monetary cost alone of trying to monitor criminal activities that are conducted online puts a burden on law enforcement agencies and Governments. The Silk Road is a dark net market or an online black market known for the sale of illegal drugs (Dalins et al., 2018; Hayes et al., 2018). It is illegal to use websites that engage with illegal activi- 
ties. Due to the ubiquitous nature of the WWW and the anonymity provided, the dark web poses serious challenges to law enforcement agencies around the world. Law enforcement agencies can only achieve so much, members of society must be vigilant and mindful of the legality of the interactions and transactions that they conduct online. It is not only on the deep dark web that illegal activities take place, they are also conducted on the surface web, for example, sale of contraband goods, sale of replicas of branded products, sale of government services with an additional administration charge included, and so forth.

Traditional search engines or web browsers cannot access content available on the dark web. This paper reviews SNS that are accessible through the use of traditional search engines on the surface web where the content is indexed and accessible to standard web browsers. The negative effects of engaging with SNS on the surface web also relate to users engagement with the deep and dark web.

\section{Virtual Private Network (VPN)}

VPNs can be used covertly to obscure a users' browsing and online activities from prying eyes. Therefore, illegal activities and transactions can be hidden by using VPN transactions. A Virtual Private Network (VPN) enables the user to send and receive data across a public network, as if it were a private network. A Virtual Private Network (VPN) provides a means of connection to a network within an organisation (as if you were inside the organisation) even though you are not physically present. During the online session the connection is made to the remote network (within the organisation) through the VPN therefore none of the devices (printers, shared disks, and so forth) connected to the local network are available for use to the user as long as the user is remotely connected to the network within the organisation.

Figure 1 illustrates a standard connection to a network within an organisation where there is no need for a Virtual Private Network. The users' remote connection to the network of the business or organisation can be diagrammatically represented as a bubble linked to the target network working within the organization as illustrated in Figure 2.

VPNs' are used legitimately by business users to connect remotely and securely to the companies/ organisations network.

Figure 1. Connection to a network within an organization

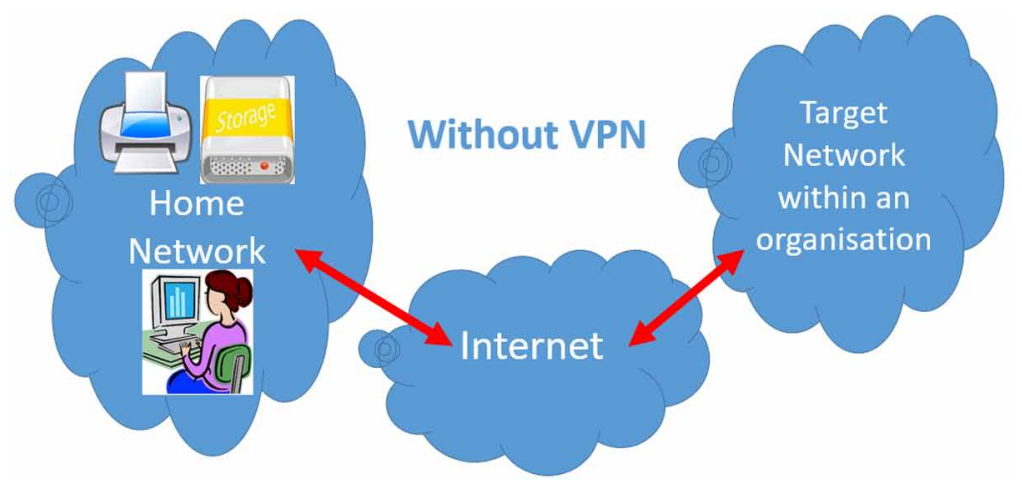


Figure 2. Connection to a network within an organisation using a VPN

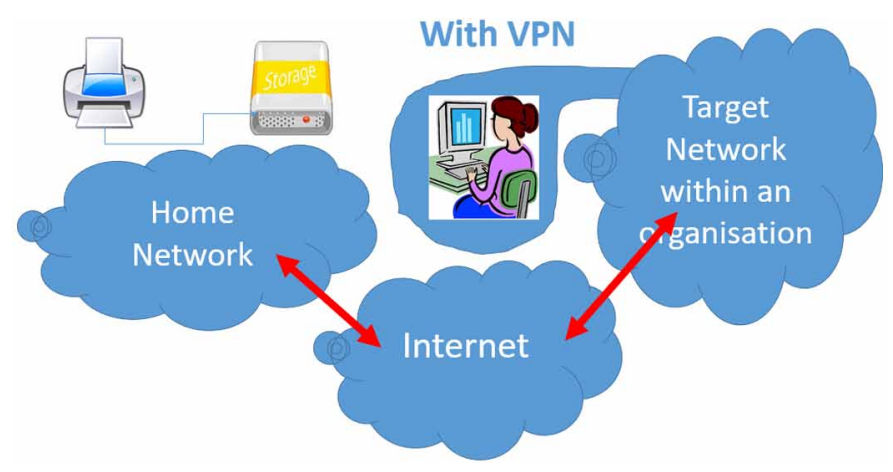

THE DARK SIDE OF ENGAGING WITH SOCIAL NETWORKING SITES (SNS)

The massive diffusion of SNS has led to some adverse and undesirable societal consequences (Salo, Mantymaki, \& Islam, 2018). SNS both on the surface web and the deep web can have a dark negative side. This chapter focuses on the dark side of engaging with SNS on the surface web. Some of the negative effects include: addiction or addictive behaviour, child pornography, cyberbullying, fake news, Fear Of Missing Out (FOMO), social comparisons, stalking, amongst many others.

\section{Addiction or Addictive Behaviour}

"The powerful and addictive sharing functionality of social media presents risks to those who share content and those who consume the content that is shared" (Baccarella et al., 2018, p. 433). Once content is shared through the use of social media, there is no knowing how many people around the world will see, download, or save the content. Shared information, pictures and videos can go viral very quickly, once this content is made publically available there is no way that anyone can delete every instance or trace of the content. In a study conducted by Wang et al. (2018) the findings suggest that addiction to SNS could potentially be a risk factor for the onset of depression in teenagers. The suggestion that addiction to social networking sites could trigger depression in teenagers is a serious issue that deserves further research. Addiction to SNS could also be a risk factor for the onset of depression in adults.

Kanat-Maymon, Almog, Cohen, \& Amichai-Hamburger (2018) suggest that the roles of self-esteem and contingent self-worth (CSW) may possibly be associated with excessive and inappropriate use of SNS. It is impossible to know the extent to which users are involved with or subjected to inappropriate use of SNS. In a study conducted by (Atroszko et al., 2018) the findings suggest that "When suggested tentative personality risk factors model were investigated, addictive Facebook use was related to being female, being older, extraverted, narcissistic, having low self-efficacy as well as feeling loneliness and social anxiety" (Atroszko et al., 2018, p. 335). Unfortunately, some users do not realise the negative effects that addictive use of SNS can have on their lives and the lives of others. The findings of Casale \& Fioravanti (2018) suggest that there is "a positive association between grandiose narcissism and problematic SNS use" (p. 317). SNS are a recent phenomenon in the history of mankind, further research is needed to ascertain the influence of addictive use of SNS on personal relationships and general well-being.

Excessive use of modern technological devices for social networking can have negative consequences on the following: quality time spent engaging with friends and family (Osatuyi \& Turel, 2018), work environment and performance (Moqbel \& Kock, 2018; Osatuyi \& Turel, 2018), exercising, involvement 
with many other activities that are good for both physical and mental welfare, and a reduction in positive emotions (Moqbel \& Kock, 2018). "Facebook addiction is related to higher stress, lower general health and lower sleep quality" (Atroszko et al., 2018, p. 335). These negative effects need to be taken seriously and appropriately addressed.

Internet addiction is a recent and changing phenomenon (Mubarak \& Quinn, 2017), which has not previously affected society as other addictions have done, therefore, further research is required to promote official recognition of this problem and possibly identify suitable treatments to resolve this problem before social engagement is negatively affected by obsessive use of the internet and SNS. Mubarak \& Quinn (2017) suggest that "it is likely that individuals experiencing internet addiction may engage in problem behaviours in cyberspace and create social and psychological problems to other internet users" (p. 9).

\section{Child Pornography}

Dalins, Wilson \& Carman (2018) suggest that law enforcement agencies show more concern for sites hosting Child Exploitation Materials (CEM) than sites hosting child pornography in the form of cartoons. The sharing of content depicting the exploitation of children for the gratification of others poses a serious challenge to law enforcement agencies. Child pornography and exploitation occurs almost $25 \%$ more often than adult pornography (Dalins et al., 2018).

"One site advertised itself as a 'support' forum, though in terms of supporting and normalizing paedophilia rather than aiding persons avoid such behavior and actions" (Dalins et al., 2018, p. 71), whilst other sites offered education and training on grooming vulnerable children (Dalins et al., 2018). SNS within the deep and dark web require policing by government supported agencies to infiltrate such sites and monitor the activities of people engaging with these sites.

\section{Cyberbullying}

In a study conducted by Mc Hugh, Wisniewski, Rosson, \& Carroll (2018) the findings were that "cyberbullying, sexual solicitations, and exposure to explicit content (but not information breaches) can cause symptoms of PTSD” (p. 1182). Post-Traumatic Stress Disorder (PTSD) is a mental health disorder that effects some people who have been exposed to or have personally experienced some horrifying event, or others who have witnessed such events. Experiencing PTSD as a result of engaging with SNS indicates that there is a dark side to SNS. The Health Service Executive (HSE) have provided on their website some helpful advice and who to contact regarding online bullying (HSE, 2018a). "Cyberbullying may be a way to intentionally harm individuals, while oversharing photos of positive experiences unintentionally causes anxiety among those who live lives less glamorous" (Baccarella et al., 2018, p. 432). Some users may not intentionally aim to harm other users by oversharing, not all users will be harmed by the positive posts of others, but some users may through social comparison feel that their lot in life is not as glamorous or successful as others.

\section{Fake News}

Fake news is the spreading of untrue facts online or through SNS that may influence readers' opinions, voting choices, or even, election outcomes. SNS can be used to spread fake news (Baccarella et al., 2018). Users need to be discerning about what they read and what they believe. "Although the actual effect of fake news online on voters' decisions is still unknown, concerns over the perceived effect of fake news 
online have prevailed in the US and other countries" (Jang \& Kim, 2018, p. 295). Throughout history there has always been concerns with fake news, alternatively known as propaganda. "The unprecedented popularity of social media for gathering news raises a number of critical questions regarding who trusts news in social media and what sites we trust" (Warner-Soderholm et al., 2018, p. 309). Fake news could have the potential to influence political appointments and could possibly even destroy lives. Some people may not know what or who to believe anymore which may lead to mental stress.

\section{Fear of Missing Out (FOMO)}

Fear of Missing Out (FOMO) has the greatest impact on the level of fatigue experienced by users of social media (Bright \& Logan, 2018). Lack of sleep can lead to various different mental health disorders. FOMO can have an adverse effect on people's lives, as an obsession with wanting to keep up with what everyone else is doing, can lead to user fatigue and other adverse consequences. Nicholar Carr (2010) argued the point that people's attention span has diminished as a result of engaging with the internet and all it offers. "The Shallows: what the internet is doing to our brains" by Nicholar Carr (2010) is an insightful, inspirational, and influential book. After reading this book, one reader selected to "unsubscribe" from numerous e-mail lists, while others deactivated a number of SNS accounts. "The Circle" by Dave Eggers (2013) is another book that would really make the reader consider the amount of information that is shared online, and how all the data mining conducted by organisations is affecting our privacy.

The data mining conducted by some SNS can also affect the privacy of owners and employees of these organisations. Hackers over the years have gained access to information from many organisations around the world proving that there is no way to safely protect one's privacy. Should an organization which runs a SNS be fined by the European Union for breach of privacy rights, this fine will not bring back the privacy that has been lost to all the users.

Even if an individual is extremely cautious about their own personal information and mindful of every piece of data they share online, others, can upload personal information and images of that person without their explicit permission. This happens all the time and the effort it takes for an individual to get this content taken back down from SNSs is extensive.

In life, it is so easy to go with the flow, without even considering what effects our actions are having on our daily lives and the daily lives of loved ones. It is so easy to get drawn into engaging with online activities, that hours can pass and be lost to the user, which could have been spent engaging with friends, doing productive work, getting exercise, or focusing on things that really matter in life. Some people are so busy recording every meal and experience to post pictures online, that they are not really focusing on the moment, relaxing, and enjoying the time spent with friends. Man has inhabited this earth for years without the need for all this connectivity and lack of privacy. Perhaps one of the reasons obesity and diabetes are on the increase is because mankind now devotes so much time online due to FOMO. If only people would consider what they are missing out by spending so much time online they might then start to relax and enjoy their own life instead of trying to imitate the lives of others as portrayed online.

\section{Social Comparisons}

As a result of using SNS some people may get the impression that others posting to the same SNS are leading better lives in comparison to their own. A survey among Korean females found that social comparison was positively associated with the use of blogs, Instagram, and LinkedIn (Chae, 2018). Engagement with SNS can produce social comparison with others (Wang et al., 2018) which may result 
in feelings of loneliness in others (Sutcliffe, Binder, \& Dunbar, 2018), isolation, anxiety and possibly depression. Online users tend to share the highlights of their lives which may not be representative of the real lives that they are living on a day to day basis. "Those with a high social comparison orientation should limit their use of social media to avoid emotional stress" (Chae, 2018, p. 1663). One's self esteem can be adversely affected through social comparison with others. As long as people do not realise the potential damage of engaging with SNS they may continue to suffer from social comparisons with others which could lead to mental health issues.

\section{Stalking}

Some SNS have the ability to capture a person's current location through Internet Protocol (IP) address information, this functionality can be used to track or monitor the whereabouts of others (Baccarella et al., 2018). The fact that the location of a person can be tracked may possibly be reassuring to some, for example, parents who have given a mobile phone to a child may then be able to obtain knowledge of their whereabouts at all times. Alternatively, a person's location may be tracked without their knowledge or permission through the use of technology, by someone who is interested in their whereabouts or someone who holds a grudge, therefore, it is an invasion of personal privacy, ethically unacceptable, and potentially a safety threat. "Studies indicate a strong correlation between high Facebook usage and jealousy in relationships; in other words, as Facebook usage increases, so does jealousy" (Warner-Soderholm et al., 2018, p. 306). Some users may get unrealistic expectations of what life should be like, based on how others portray their lives to be online, this can lead to feelings of jealousy. Some may suffer from negative body image if they compare their body to those of others as they are depicted online. Some images available online may have been photo shopped to make them appear more appealing. Jealously in relationships can lead to serious mental problems which can only get worse if one continues to stalk others and compare themselves to others as portrayed online.

\section{SOLUTIONS AND RECOMMENDATIONS}

The dark side of engaging with SNS will continue to pose problems to society in general as long as people allow SNS to take up too much of their valuable time and influence how they feel about themselves and others. To avoid undue emotional stress, users who are susceptible to a high social comparison orientation should reduce the time spent engaging with SNS (Chae, 2018), or cease to engage with SNS altogether.

Cyberbullying has the potential for serious consequences, for example, someone may feel so bad from being a victim of cyberbullying that they may consider taking their own life by committing suicide (Cohen-Almagor, 2018), or doing something else extreme. "Suicide is a major public health problem and is the second leading cause of death in young people worldwide. Indicating a lack of adequate treatment approaches, recent data suggest a rising suicide rate" (Bailey, Rice, Robinson, Nedeljkovic, \& AlvarezJimenez, 2018, p. 499). Government funded supports are available, for example a helpline to listen to victims and help them to deal effectively with the problem (HSE, 2018a, 2018b). Unfortunately, not all victims of online bullying are aware of these services. People of all ages can be victims of cyberbullying and government provided supports should be available to help and guide all victims about the best ways to deal with the online persecution.

SNS can be used to advertise and sell all sorts of goods, including drugs and other illegal products. Concerted efforts by law enforcement agencies, the public, public health authorities, government ad- 
ministrators, and technology companies will be required to successfully combat the sale of illegal drugs online (Mackey, 2018). Due to the complexities involved in dealing with cybercrimes "too few appear currently willing or able to grapple with the issues, let alone provide satisfying answers" (Slaughter, 2018, p. 118). Further research is required to determine the most productive and cost effective methods to combat cybercrimes.

Organisations' should leverage their information security policies based on the perceived threats and benefits of employees engaging with SNS (Silic \& Back, 2016). Should an employee be addicted to engaging with SNS and possibly engage during working hours, then the work that they are supposed to be doing may be neglected. Organisations' should be aware of the perceived threats and benefits of SNS, so that they can effectively deal with these by taking appropriate action. "Fake news is a critical major issue that social networking websites can ameliorate with vigilance and skillful use of technology" (Morales, Sosa-Fey, \& Farias, 2017, p. 87). Fake news poses a real challenge to society and requires further investigation.

\section{FUTURE RESEARCH DIRECTIONS}

Further research is required to determine the most productive and cost effective methods to combat cybercrimes. Law enforcement agencies and Governments have numerous challenges ahead in dealing with the dark side of SNS and cybercrime on the surface web. This is only scratching the surface as the deep and dark web are more embedded in areas where users want to hide their identity, therefore, it is much more difficult to trace the online actions of users.

Fake news has the potential to influence politics and also to destroy lives. Fake news poses a real challenge to society and requires further investigation. Members of society deserve to know the truth so that they can make informed decisions based on honest facts.

The suggestion that addiction to SNS could trigger depression in teenagers is a serious issue that deserves further research. Internet addiction is a recent and changing phenomenon (Mubarak \& Quinn, 2017), which has not previously impacted on society as other addictions have done, therefore, further research is required to promote official recognition of this problem. SNS are a recent phenomenon in the history of mankind, further research is needed to ascertain the influence of addictive use of SNS on personal relationships and general well-being.

\section{CONCLUSION}

Although SNS are used by many people all around the world to connect with loved ones and friends in a positive context, alas, SNS are also used by many people in a negative context, including some of the topics discussed in this chapter. There are some dark sides or negative aspects to human engagement with SNS which may include the following: exposure to possible risks, spending too much time online, deleterious impacts, access to black market traders, untraceable cryptocurrencies, sale of drugs and firearms, child pornography, trade in exotic animals, identity theft, and money laundering.

Some concerns with users' engagement with SNS are as follows: images going viral, internet addiction, depression in teenagers, lack of quality time to spend with friends and family, impact on work performance, physical and mental welfare, higher stress levels, lack of sleep, loneliness, isolation, anxiety, and jealousy, amongst many others. 
These negative effects need to be taken seriously and appropriately addressed. Users should be encouraged to question the short and long term risks of engaging with SNS. Users of Social Networking Sites within the surface web and the deep and dark web require the support of government agencies in dealing with the inappropriate activities of other people engaging with these sites. The monetary cost of dealing with cybercrime puts a burden on Law Enforcement Agencies and Governments.

Society as a whole needs to consciously consider all of the negative effects of engagement with SNS, discuss these with friends, family, and work colleagues then try to reach a consensus on how best to address all of these issues.

\section{REFERENCES}

Atroszko, P., Balcerowska, J., Bereznowski, P., Biernatowska, A., Pallesen, S., \& Andressen, C. (2018). Facebook addiction among Polish undergraduate students: Validity of measurement and relationship with personality and well-being. Computers in Human Behavior, 85, 329-338. doi:10.1016/j.chb.2018.04.001

Baccarella, C., Wagner, T., Kietzmann, J., \& McCarthy, I. (2018). Social media? It's serious! Understanding the dark side of social media. European Management Journal, 36(4), 431-438. doi:10.1016/j. emj.2018.07.002

Bailey, E., Rice, S., Robinson, J., Nedeljkovic, M., \& Alvarez-Jimenez, M.(2018). Theoretical and empirical foundations of a novel online social networking intervention for youth suicide prevention: A conceptual review. Journal of Affective Disorders, 238, 499-505. doi:10.1016/j.jad.2018.06.028 PMID:29936387

Bright, L., \& Logan, K. (2018). Is my fear of missing out (FOMO) causing fatigue? Advertising, social media fatigue, and the implications for consumers and brands. Internet Research, 28(5), 1213-1227. doi:10.1108/IntR-03-2017-0112

Carr, N. (2010). The Shallows: what the internet is doing to our brains. New York, NY: W. W. Norton \& Company.

Casale, S., \& Fioravanti, G. (2018). Why narcissists are at risk for developing Facebook addiction: The need to be admired and the need to belong. Addictive Behaviors, 76, 312-318. doi:10.1016/j.addbeh.2017.08.038 PMID:28889060

Chae, J. (2018). Reexamining the relationship between social media and happiness: The effect of various social media platforms on reconceptualized happiness. Telematics and Informatics, 35(6), 1656-1664. doi:10.1016/j.tele.2018.04.011

Cohen-Almagor, R. (2018). Social responsibility on the Internet: Addressing the challenge of cyberbullying. Aggression and Violent Behavior, 39, 42-52. doi:10.1016/j.avb.2018.01.001

Dalins, J., Wilson, C., \& Carman, M. (2018). Criminal motivation on the dark web: A categorisation model for law enforcement. Digital Investigation, 24, 62-71. doi:10.1016/j.diin.2017.12.003

Eggers, D. (2013). The Circle. McSweeney's Books.

Eirinaki, M., Gao, J., Varlamis, I., \& Tserpes, K. (2018). Recommender systems for large-scale social networks: A review of challenges and solutions. Future Generation Computer Systems, 78, 413-418. doi:10.1016/j.future.2017.09.015 
Facebook. (2018). Connect with friends and the world around you on Facebook. Retrieved from https:// www.facebook.com/

Firefox. (2019). Mozilla Firefox. Retrieved from https://www.mozilla.org/en-US/firefox/new/

Flickr. (2018). Flickr at its best is a place to connect, to discover, and to evolve as photographers and lovers of photography. Retrieved from https://www.flickr.com/

Google+. (2018). Collections. Retrieved from https://plus.google.com/discover

Google. (2019). Google Chrome. Retrieved from https://www.google.com/chrome/?brand=CHBD\& gclid=EAIaIQobChMI1L2JsqmB4AIVqrXtCh226QumEAAYASAAEgLzZvD_BwE\&gclsrc=aw.ds

Grindr. (2018). The World's largest social networking app for gay, bi, trans, and queer people. Retrieved from https://www.grindr.com/

Guinta, M., \& John, R. (2018). Social media and adolescent health. Pediatric Nursing, 44, 196-201.

Hayes, D., Cappa, F., \& Cardon, J. (2018). A framework for more effective dark web marketplace investigations. Information, 9(186), 1-17.

HSE. (2018a). Bullying and harassment Bullying can affect anyone. It isn't always easy to deal with a bully, no matter your age. Retrieved from https://www2.hse.ie/wellbeing/mental-health/bullyingand-harassment.html?gclid=EAIaIQobChMIoaX58ZfA4QIVz53tCh1GSQDPEAAYASAAEgLU7 fD_BwE\&gclsrc=aw.ds

HSE. (2018b). Cyberbullying is a new form of bullying, but it can be even more harmful than one might think. Retrieved from https://www2.hse.ie/wellbeing/mental-health/cyberbullying.html

Instagram. (2018). Sign up to see photos and videos from your friends. Retrieved from https://www. instagram.com/

Jang, S., \& Kim, J. (2018). Third person effects of fake news: Fake news regulation and media literacy interventions. Computers in Human Behavior, 80, 295-302. doi:10.1016/j.chb.2017.11.034

Kanat-Maymon, Y., Almog, L., Cohen, R., \& Amichai-Hamburger, Y. (2018). Contingent self-worth and Facebook addiction. Computers in Human Behavior, 88, 227-235. doi:10.1016/j.chb.2018.07.011

LinkedIn. (2018). Your dream job is closer than you think. Retrieved from https://www.linkedin.com

Liu, F., \& Lee, H. (2010). Use of social network information to enhance collaborative filtering performance. Expert Systems with Applications, 37(7), 4772-4778. doi:10.1016/j.eswa.2009.12.061

Mackey, T. (2018). Opioids and the Internet: Convergence of technology and policy to address the illicit online sales of opioids. Health Services Insights, 11, 1-6. doi:10.1177/1178632918800995 PMID:30245569

McHugh, B., Wisniewski, P., Rosson, M., \& Carroll, J. (2018). When social media traumatizes teens: The roles of online risk exposure, coping, and post-traumatic stress. Internet Research, 28(5), 1169-1188. doi:10.1108/IntR-02-2017-0077

Microsoft. (2019). Windows Internet Explorer. Retrieved from https://www.microsoft.com/en-us/download/internet-explorer.aspx 
Monk, B., Mitchell, J., Frank, R., \& Davies, G. (2018). Uncovering Tor: An examination of the network structure. Security and Communication Networks, 2018, 1-12. doi:10.1155/2018/4231326

Moqbel, M., \& Kock, N. (2018). Unveiling the dark side of social networking sites: Personal and workrelated consequences of social networking site addiction. Information \& Management, 55(1), 109-119. doi:10.1016/j.im.2017.05.001

Morales, K., Sosa-Fey, J., \& Farias, J. (2017). Social Media: Are the benefits worth the risks for business? International Journal of Business and Public Administration, 14(1), 87-97.

Mubarak, A., \& Quinn, S. (2017). General strain theory of Internet addiction and deviant behaviour in social networking sites (SNS). Journal of Information, Communication and Ethics in Society. doi:10.1108/ JICES-08-2016-0024

Norbutas, L. (2018). Offline constraints in online drug marketplaces: An exploratory analysis of a cryptomarket trade network. The International Journal on Drug Policy, 56, 92-100. doi:10.1016/j. drugpo.2018.03.016 PMID:29621742

Osatuyi, B., \& Turel, O. (2018). Tug of war between social self-regulation and habit: Explaining the experience of momentary social media addiction symptons. Computers in Human Behavior, 85, 95-105. doi:10.1016/j.chb.2018.03.037

Paul, K. (2018). Ancient artifacts vs. digital artifacts: New tools for unmasking the sale of illicit antiquities on the Dark Web. Arts, 7(12), 1-19.

Pinterest. (2018). Pinterest helps you find ideas to try. Retrieved from https://www.pinterest.ie/

Porter, K. (2018). Analyzing the DarkNetMarkets subreddit for evolutions of tools and trends using LDA topic modeling. Digital Investigation, 26, S87-S97. doi:10.1016/j.diin.2018.04.023

QZone. (2018). Retrieved from https://qzone.qq.com/

Reddit. (2018). Reddit: the front page of the internet. Retrieved from https://www.reddit.com/

Salo, J., Mantymaki, M., \& Islam, A. (2018). The dark side of social media - and Fifty Shades of Grey introduction to the special issue: The dark side of social media. Internet Research, 28(5), 1166-1168. doi:10.1108/IntR-10-2018-442

Silic, M., \& Back, A. (2016). The dark side of social networking sites: Understanding phishing risks. Computers in Human Behavior, 60, 35-43. doi:10.1016/j.chb.2016.02.050

Skype. (2018). Skype makes it easy to stay in touch. Retrieved from https://www.skype.com

Slaughter, R. (2018). The IT revolution reassessed part one: Literature review and key issues. Futures, 96, 115-123. doi:10.1016/j.futures.2017.12.006

Snapchat. (2018). A new way to look. Retrieved from https://www.snapchat.com/

Sutcliffe, A., Binder, J., \& Dunbar, R. (2018). Activity in social media and intimacy in social relationships. Computers in Human Behavior, 85, 227-235. doi:10.1016/j.chb.2018.03.050

Tinder. (2018). Match. Chat. Date. Retrieved from https://tinder.com 
Tumblr. (2018). Come for what you love. Stay for what you discover. Retrieved from https://www. tumblr.com/

Twitter. (2018). See what's happening in the world right now. Retrieved from https://twitter.com

Viber. (2018). Free and secure calls and messages to anyone, anywhere. Retrieved from https://www. viber.com/

Wang, P., Wang, X., Wu, Y., Xie, X., Wang, X., Zhao, F., ... Lei, L. (2018). Social networking sites addiction and adolescent depression: A moderated mediation model of rumination and self-esteem. Personality and Individual Differences, 127, 162-167. doi:10.1016/j.paid.2018.02.008

Warner-Soderholm, G., Bertsch, A., Sawe, E., Lee, D., Wolfe, T., Meyer, J., ... Fatilua, U. (2018). Who trusts social media? Computers in Human Behavior, 81, 303-315. doi:10.1016/j.chb.2017.12.026

Wegberg, R., Oerlemans, J., \& Deventer, O. (2018). Bitcoin money laundering: Mixed results? An explorative study on money laundering of cybercrime proceeds using bitcoin. Journal of Financial Crime, 25(2), 419-435.

WhatsApp. (2018). Simple. Secure. Reliable messaging. Retrieved from https://www.whatsapp.com/

YouTube. (2018). Best of YouTube. Retrieved from https://www.youtube.com/

\section{ADDITIONAL READING}

Ampong, G., Mensah, A., Adu, A., Addae, J., Omoregie, O., \& Ofori, K. (2018). Examining self-disclosure on social networking sites: A flow theory and privacy perspective. Behavioral Science, 8(58), 1-17. PMID:29882801

Errasti, J., Amigo, I., \& Villadangos, M. (2017). Emotional uses of Facebook and Twitter: Its relation with empathy, narcissism, and self-esteem in adolescence. Psychological Reports, 120(6), 997-1018. doi:10.1177/0033294117713496

Fox, J., \& Moreland, J. (2015). The dark side of social networking sites: An exploration of the relational and psychological stressors associated with Facebook use and affordances. Computers in Human Behavior, 45, 168-176. doi:10.1016/j.chb.2014.11.083

Parks, R., Lowry, P., Wigand, R., Agarwal, N., \& Williams, T. (2018). Why students engage in cybercheating through a collective movement: A case of deviance and collusion. Computers \& Education, 125, 308-326. doi:10.1016/j.compedu.2018.04.003

Quach, S., \& Thaichon, P. (2018). Dark motives-counterfeit selling framework: An investigate on the supply side of the non-deceptive market. Marketing Intelligence \& Planning, 36(2), 245-259. doi:10.1108/ MIP-04-2017-0069

Sapountzi, A., \& Psannis, K. (2018). Social networking data analysis tools \& challenges. Future Generation Computer Systems, 86, 893-913. doi:10.1016/j.future.2016.10.019 
Topaloglu, M., Caldibi, E., \& Oge, G. (2016). The scale for the individual and social impact of students' social network use: The validity and reliability studies. Computers in Human Behavior, 61, 350-356. doi:10.1016/j.chb.2016.03.036

Zhang, X., Shan, L., Chen, X., Wang, L., Gao, B., \& Zhu, Q. (2018). Health information privacy concerns, antecedents, and information disclosure intention in online health communities. Information \& Management, 55(4), 482-493. doi:10.1016/j.im.2017.11.003

\section{KEY TERMS AND DEFINITIONS}

Addiction or Addictive Behaviour: Actions which a person can no longer control. Someone may go online to send an e-mail, get distracted and remain online for several hours, and possibly forget to send the e-mail.

Child Pornography: Online sharing of content which shows the sexual exploitation of children.

Cyberbullying: A form of bullying that occurs online.

Dark Web: The dark web refers to a number of anonymously hosted websites on the deep web which are accessible by using specialized software to hide the internet protocol (IP) address.

Fear of Missing Out (FOMO): Some people are afraid to go offline in case they miss out on some exciting piece of news.

Fake News: The spreading of untrue facts online or through Social Networking Sites that may influence readers' opinions, voting choices, and election outcomes.

IP Address: IP addresses are assigned to every device that connects to the internet.

Social Comparisons: As a result of using social networking sites some people may get the impression that other users are leading better lives in comparison to their own.

Social Networking Sites: Social networking sites (SNS) enable users to interact with other people online; similar to how people may socially interact offline by sharing personal experiences, images, making plans, and so forth.

Stalking: A person's location may be tracked without their knowledge or permission through the use of technology, by someone who is interested in their whereabouts or someone who holds a grudge; therefore, it is an invasion of personal privacy, ethically unacceptable, and potentially a safety threat.

Virtual Private Network (VPN): A virtual private network (VPN) provides a means of connecting to a network within an organisation (as if you were inside the organisation) even though you are not physically present. 